\title{
招待講演 3
}

\section{PREVENTION OF RECURRENT ISCHEMIC STROKE}

\author{
JP Mohr, MS MD \\ Neurological Institute New York City 10032
}

The Warfarin-Aspirin Recurrent Stroke Study : For stroke patients with no atrial fibrillation or symptomatic carotid stenosis, the long-standing argument whether the success of warfarin with atrial fibrillation would show comparable effects for those without obvious cardiogenic stroke risk factors is better understood with the recent publication of the Warfarin Aspirin Recurrent Stroke Study (WARSS). Initial results from the recent warfarin-aspirin recurrent stroke study (WARSS) compared aspirin $325 \mathrm{mg}$ q. $\mathrm{d}$. against adjusted dose warfarin (INR 1.4-2.8) in double blind fashion for secondary prevention after lacunar, atherosclerotic, or cryptogenic stroke. WARSS also showed no statistically significant difference in the low $(<2 \%)$ serious hemorrhagic adverse event rates in the two treatment arms and no statistically significant difference in the treatment effects between warfarin or aspirin. The warfarin effect showed, as it did in atrial fibrillation trials, a suppression effect on recurrent ischemic stroke appearing over the INR exceeded 1.5 and remained relatively stable over the entire INR range up to 3.0.

Rates in WARSS for minor hemorrhage were significantly higher for warfarin than for aspirin, a finding replicated in other trials. For serious or major hemorrhage, concerns of hazard appeared well justified for INR ranges $>2.5$. Complications have been well documented in trials with no prior stroke, ${ }^{123}$ as well as in the stroke population, mainly elderly and at higher risk for hemorrhage. ${ }^{456}$ Higher INR ranges than those used in WARSS have also had mixed results in non-stroke settings where warfarin was compared with $^{7}$ or in combination with aspirin. ${ }^{8}$

Because WARSS failed to confirm statistically significant differential therapeutic effects for any clinically identifiable subtypes of ischemic stroke, it remains unclear whether warfarin can be said to be justified for any but obvious cardioembolic strokes. Although not powered to address effects by stroke subtype, WARSS suggests some possible selective treatment effects. The aspirin effect was the largest in the small (259 patients) large-artery stroke subgroup, but the significance of such findings is blunted by the large confidence intervals around the point estimate. This stroke subtype, fully defined, is currently being pursued in a trial seeking a large warfarin benefit. ${ }^{9}$ Lacunes (1237 patients) also showed a possible aspirin benefit, supporting suggestions of a pathophysiologic link to large intracranial artery atheroma. ${ }^{101}$ Cryptogenic stroke, inferred to represent clinically-occult embolism ${ }^{12}$ or coagulopathies. ${ }^{12}$ was the only clinically-identified stroke subtype suggesting a possible warfarin benefit, but with a small $(8 \%)$ risk reduction, also not statistically significant.

Platelet antiaggregant therapies : In the European Stroke Prevention Study II - (ESPS II) the combination of $25 \mathrm{mg}$ aspirin and $200 \mathrm{mg}$ extended-release dipyridamole (each twice daily) was found superior to aspirin alone in the prevention of recurrent ischemic stroke. ${ }^{13}$ Though not tested in a setting of acute cerebral ischemia alone, clopidogrel may be used for patients with medical (gastrointestinal or respira- 
tory) contraindications against aspirin. CAPRIE was a randomized, double blind, international trial of 19,185 patients at 384 centers in 16 countries and reported as a primary outcome was the combination of ischemic stroke, myocardial infarction, or vascular death during $1-3$ year follow-up period. Patients treated with clopidogrel had a $5.32 \%$ annual risk of ischemic stroke, myocardial infarction or vascular death, whereas patients treated with aspirin had a $5.83 \%$ annual risk of the same events. These rates showed a statistically significant $(\mathrm{p}=0.043)$ but tiny relative-risk reduction of $8.7 \%$ in favor of clopidogrel (95\% CI 0.3-16.5). These seem rather narrow benefits to many of us and the subset for stroke alone showed no statistically significant benefit. ${ }^{14}$ A trial comparing clopidogrel plus aspirin versus aspirin alone for recurrent ischemic stroke (MATCH) hes completed enrollment, but no results are yet available.

Those inclined to choose antiplatelet therapy, aspirin or others, ${ }^{15}$ have support for their choice in the overall intent-to-treat result from WARSS. Those inclined toward warfarin may express dissatisfaction with certain aspects of the WARSS design (e. g. ,INR range, clinical subtype inclusion/exclusions) and await the next series of reports from this database. Such possible differential treatment effects were the basis for two of the four parallel studies for WARSS. However, neither the status of antiphospholipids (APASS), nor patent cardiac foramen ovale (PICSS), ${ }^{1617}$ showed any effect for warfarin, nor for the presence of either condition as a risk for recurrent (as opposed to initial) ischemic stroke.

Combined warfarin and aspirin therapy: Painful experience argues against the simple assumption that aspirin and warfarin can be combined safely in the prevention of recurrent ischemic stroke. No trial has directly assessed this point but 'stroke' as an outcome in several trails suggests clinicians will be disappointed when they infer that the two agents can be managed safely if the INR is kept in the rage < $3.0 .^{18}$ Our initial enthusiasm for mounting a warfarin + aspirin WARSS-II have been greatly blunted by these findings.

Other therapies : A rising tide of evidence indicates the use of anti-hypertensives of almost any class (ACE inhibitors, beta-blockers, calcium antagonists, with or without diuretics) has raised hopes there could be reduction in recurrent stroke from the addition of these therapies to an antithrombotic program. Thus far, a gratifying risk reduction $(43 \%)$ has been seen for stroke in at least one trial of perindopril and the diuretic indapamide (PROGRESS). ${ }^{19}$ Even given that editorials suggest the risk reduction was from combined therapy and not from the ACE inhibitor alone, there are clearly new directions that give hope for polytherapies.

\section{References}

${ }^{1}$ Gullov AL, Koefoed BG, Petersen P. Bleeding during warfarin and aspirin therapy in patients with atrial fibrillation : the AFASAK 2 study. Atrial Fibrillation Aspirin and Anticoagulation. Arch Intern Med. $1999 ; 159: 1322-8$.

${ }^{2}$ Yamaguchi $T$. Optimal intensity of warfarin therapy for secondary prevention of stroke in patients with nonvalvular atrial fibrillation : a multicenter, prospective, randomized trial. Japanese Nonvalvular Atrial Fibrillation-Embolism Secondary Prevention Cooperative Study.Group. Stroke $2000 ; 31: 817-21$.

${ }^{3}$ Pengo V, Legnani C. Noventa F, Palareti G. Oral anticoagulant therapy in patients with nonrheumatic 
atrial fibrillation and risk of bleeding. A Multicenter Inception Cohort Study. ISCOAT Study Group. Italian Study on Complications of Oral Anticoagulant Therapy. Thromb Haemoșt. $2001 ; 85: 418-22$.

${ }^{4}$ Liu M, Counsell C, Sandercock P. Anticoagulants for preventing recurrence following ischaemic stroke or transient ischemic attack (Cochrane Review). The Cochrane Library, Issue 1, 2001.

${ }^{5}$ Go AS, Hylek EM, Phillips KA, Borowsky LH, Henault LE, et al. Implications of stroke risk criteria on the anticoagulation decision in nonvalvular atrial fibrillation : the Anticoagulation and Risk Factors in Atrial Fibrillation (ATRIA) study. Circulation. 2000;102:11-3.

${ }^{6}$ Gorter JW: Major bleeding during anticoagulation after cerebral ischemia : patterns and risk factors. Stroke Prevention In Reversible Ischemia Trial (SPIRIT). European Atrial Fibrillation Trial (EAFT) study groups. Neurology $1999 ; 53: 1319-27$.

${ }^{7}$ Witte K, Thackray S, Clark AL, Cooklin M, Cleland JG. Clinical trials.update : IMPROVEMENT-HF, COPERNICUS, MUSTIC, ASPECT-II, APRICOT and HEART. Eur J Heart Fail $2000 ; 2: 455-60$.

${ }^{8}$ Huynh T, Théroux P, Bogaty P, Nasmith J, Solymoss S. Aspirin, Warfarin, or the Combination for Secondary Prevention of Coronary Events in Patients With Acute Coronary Syndromes and Prior Coronary Artery Bypass Surgery. Circulation. $2001 ; 103: 3069$.

${ }^{9}$ The Warfarin-Aspirin Symptomatic Intracranial Disease (WASID) Study Group. Prognosis of patients with symptomatic vertebral or basilar artery stenosis. Stroke $1998 ; 29: 1389-92$.

${ }^{10}$ Fisher CM. The arterial lesions underlying lacunes. Acta Neuropathol (Berl). $1968 ; 12: 1-15$.

${ }^{11}$ Kappelle LJ, van Latum JC, van Swieten JC, Algra A, Koudstaal PJ, et al. Recurrent stroke after transient ischaemic attack or minor ischaemic stroke : does the distinction between small and large vessel disease remain true to type? Dutch TIA Trial Study Group. J Neurol Neurosurg Psychiatry. 1995 ; 59 : $127-$ 31.

${ }^{12}$ Bushnell CD, Goldstein LB. Diagnostic testing for coagulopathies in patients with ischemic stroke. Stroke $2000 ; 31: 3067-78$.

${ }^{13}$ Diener HC, Cunha L, Forbes C, et al. European Stroke Prevention Study 2. Dipyridamole and acetylsalicylic acid in the secondary prevention of stroke. J. Neurol. Sci. $1996 ; 143: 1-13$

${ }^{14}$ CAPRIE Steering Committee. A randomized, blinded, trial of clopidogrel versus aspirin in patients at risk for ischemic events (CAPRIE). Lancet 1996;348: 1329-39.

${ }^{15}$ Easton JD. Future Perspectives for Optimizing Oral Antiplatelet Therapy: Cerebrovasc Dis. $2001 ; 11$ Suppl S2:23-28.

${ }^{16}$ Sacco RL, Homma S, Di Tullio MR. Patent foramen ovale : a new risk factor for ischemic stroke. Heart Dis Stroke. $1993: 2: 235-41$.

${ }^{17}$ Homma S, Di Tullio MR. Sacco RL, Mihalatos D, Li Mandri G, Mohr JP. Characteristics of patent foramen ovale associated with cryptogenic stroke. A biplane transesophageal echocardiographic study. Stroke. $1994 ; 25: 582-6$

${ }^{18}$ Coletta AP, Cleland JG. Clinical trials update : highlights of the scientific sessions of the XXIII Congress of the European Society of Cardiology-WARIS II, ESCAMI, PAFAC, RITZ-1 and TIME. Eur J Heart Fail. $2001 ; 3: 747-50$.

${ }_{19}$ [No authors listed] Randomised trial of a perindopril-based blood-pressure-lowering regimen among 6.105 individuals with previous stroke or transient ischaemic attack. Lancet. $2001 ; 358: 1033-41$. 